\title{
Overcoming the Efficiency-Limiting Mechanisms in Commercial Si Solar Cells
}

B. Sopori and $W$. Chen

National Renewable Energy Laboratory

T. Tan and P. Plekhanov

Duke University, Raleigh, NC

Presented at the National Center for

Photovoltaics Program Review Meeting

Denver, Colorado

September 8-11, 1998

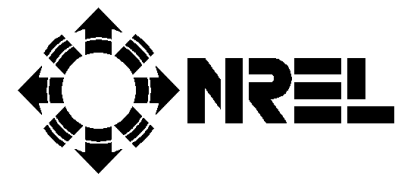

National Renewable Energy Laboratory 1617 Cole Boulevard

Golden, Colorado 80401-3393

A national laboratory of the U.S. Department of Energy Managed by Midwest Research Institute for the U.S. Department of Energy under contract No. DE-AC36-83CH10093

Work performed under task number PV902503

October 1998 


\section{NOTICE}

This report was prepared as an account of work sponsored by an agency of the United States government. Neither the United States government nor any agency thereof, nor any of their employees, makes any warranty, express or implied, or assumes any legal liability or responsibility for the accuracy, completeness, or usefulness of any information, apparatus, product, or process disclosed, or represents that its use would not infringe privately owned rights. Reference herein to any specific commercial product, process, or service by trade name, trademark, manufacturer, or otherwise does not necessarily constitute or imply its endorsement, recommendation, or favoring by the United States government or any agency thereof. The views and opinions of authors expressed herein do not necessarily state or reflect those of the United States government or any agency thereof.

Available to DOE and DOE contractors from:

Office of Scientific and Technical Information (OSTI)

P.O. Box 62

Oak Ridge, TN 37831

Prices available by calling 423-576-8401

Available to the public from:

National Technical Information Service (NTIS)

U.S. Department of Commerce

5285 Port Royal Road

Springfield, VA 22161

703-605-6000 or 800-553-6847

or

DOE Information Bridge

http://www.doe.gov/bridge/home.html 


\title{
Overcoming the Efficiency-Limiting Mechanisms in Commercial Si Solar Cells
}

\author{
Bhushan Sopori, Wei Chen, Teh Tan*, and Pavel Plekhanov* \\ National Renewable Energy Laboratory \\ 1617 Cole Boulevard, Golden, CO \\ * Duke University, Mechanical Engineering and Materials Science \\ Raleigh, $N C$
}

\begin{abstract}
A brief review of performance-limiting processes in a commercial solar cell fabricated on low-cost substrate is given. Higher efficiencies require effective gettering of precipitated impurities present at the defect clusters, and improved cell and process designs. Overcoming these limitations is expected to lead to $18 \%-20 \%$ cell efficiencies.
\end{abstract}

\section{INTRODUCTION}

From the very inception of the photovoltaic (PV) program, the favored approach to commercializing PV energy for terrestrial applications was to fabricate solar cells on low-cost silicon substrates. The basic assumption was that post-growth processes could upgrade the quality of the material. This belief led to development of many new techniques for the growth of low-cost, shaped silicon, some of which are now employed commercially. Furthermore, a considerable effort was spent on modifying $\mathrm{CZ}$ growth to meet cost considerations of the substrate. It is interesting to note that these decisions were made at a time when very little was known about the physics of the processes that would allow material quality to be upgraded in a cost-effective manner. Thus, it is rather remarkable that, about two decades later, many of these serendipitous processes actually work well (1). Much of this credit goes to teams of researchers and research programs that embarked on study of impurity gettering and defect passivation. As a result of the worldwide research efforts, a wealth of knowledge has been acquired and applied to improve the material quality as a byproduct of solar cell fabrication. Such methods have already led to commercial solar cell efficiencies in the range of $13 \%-15 \%$. However, recent research results indicate that it is possible to reach $18 \%-20 \%$ cell efficiencies on the commercial material if some of the limiting mechanisms can be ameliorated.

This short paper identifies some of the performance-limiting mechanisms in the current solar cells and addresses approaches to mitigate them.

\section{EFFICIENCY-LIMITING MECHANISMS}

It is well known that the efficiency of a solar cell, fabricated on high-quality, single-crystal Si wafer, can exceed $24 \%$ for AM1.5 illumination. This efficiency is 
limited by mechanisms like Auger recombination, bandgap narrowing, and the cell design itself. However, in commercial low-cost cells, the dominant mechanisms that limit the cell efficiency can be ascribed to (i) impurities and defects, (ii) cell design, and (iii) cell processing. Because the main scope of this paper is the material issues, and due to the limited space, we will discuss only issues related to (i) in some detail, and only make a passing mention of other areas. A detailed discussion of all the issues will, however, be given in a forthcoming publication (2). In the following sections, we will address these issues and also include a brief discussion on how one can ameliorate their influence on the cell performance.

\section{IMPURITIES AND DEFECTS IN COMMERCIAL PV-Si WAFERS}

Solar cell substrates are produced in many different ways - single crystal CZ growth, cast ingots of rectangular geometry, and ribbons. The materials used in commercial Si solar cells have high concentrations of impurities and defects. Typically, they have near-saturation levels of $\mathrm{O}$ or $\mathrm{C}$, and metallic impurities in the range of about $10^{14} / \mathrm{cm}^{3}$. In addition, they have a variety of defects that result from large thermal gradients caused by high-speed growth of the material. The dominant defect species are intragrain dislocations whose density typically averages around $10^{5} / \mathrm{cm}^{2}$. However, recent materials exhibit a tendency to form defect clusters. Figure 1 is a defect map of a commercial $10 \mathrm{~cm} \times 10 \mathrm{~cm}$ wafer that shows formation of defect clusters as dark regions in otherwise very low defect density material. An inset in the figure shows the detailed structure of the defect cluster identified in the defect map. Defect clusters consist of a high density of dislocation tangles, grain boundaries, and stacking faults (3).

Recent studies have shown that, in a high-quality commercial wafer, the defect clusters are sites of metallic impurity precipitation. Figure 2 is a TEM picture of such precipitates taken in a region of a defect cluster. The presence of precipitated impurities is in concurrence with our earlier results that show such regions have low concentrations of dissolved transition metal impurities and low minority carrier lifetimes (3).

Impurity gettering has been very effectively applied to improve the quality of the
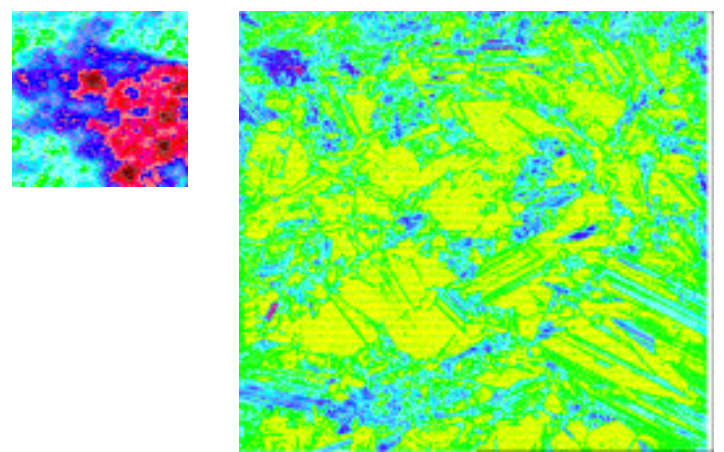

FIGURE 1. A defect map of a commercial 10-cm $\mathrm{X} 10-\mathrm{cm}$ wafer showing clustering of defects. The picture in the inset is a magnified view of the region identified hv arrows.

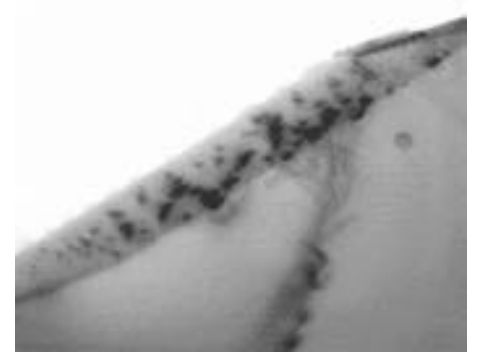

FIGURE 2. A TEM micrograph from a defect cluster region showing impurity precipitates. 
as-grown material. Because phosphorous diffusion and Al alloying are a part of standard cell processing, some degree of impurity gettering is inherent in the cell fabrication. Recent efforts at optimizing gettering as a part of solar cell fabrication has led to very high-efficiency, small-area, solar cells. However, ineffectiveness of impurity gettering continues to be a performance-limiting factor. A major reason for this is that impurity gettering is a complex process wherein a variety of interactions can take place between impurities and defects. Some of these interactions may not favor a rapid removal of impurities. Figure 3 is a schematic illustrating various mechanisms that participate in a gettering process. It shows a silicon wafer at a high temperature, with gettering region(s) on both sides that may correspond to a simultaneous gettering by $\mathrm{Al}$ and $\mathrm{P}$ diffusion. The substrate has a variety of defects. These include: vacancies and interstitial that are "frozen in" the material; extended defects such as dislocations, grain boundaries and stacking faults; inert impurities such as $\mathrm{C}$ and $\mathrm{O}$, metallic impurities such as $\mathrm{Fe}, \mathrm{Cr}, \mathrm{Ni}$ and $\mathrm{Cu}$, and precipitated impurities. A gettering process consists of removal of impurities via atomic diffusion from the gettered region(s) to the gettering region(s) where they are trapped. The dissolved transition metals, as a result of their high diffusivities, segregate in the gettering regions in a fairly short time. Clearly, a host of other processes can occur, which cannot be discussed in this brief review.

It is often assumed that the time required for out-diffusion of impurities is quite short. It is instructive to understand diffusion of impurities - both dissolved and precipitated. We can use Fe as the "test" impurity. Figure 4 shows calculated profiles, using a diffusion-segregation model, of Fe using Al alloying at $800{ }^{\circ} \mathrm{C}$ (4). We have assumed that all the Fe dissolved to a concentration of $10^{14} \mathrm{~cm}^{-3}$. It is seen that in $30 \mathrm{~min}$ the Fe concentration will reduce to about $10^{12} \mathrm{~cm}^{-3}$ and to $10^{11} \mathrm{~cm}^{-3}$ after $60 \mathrm{~min}$. In a short process, the gettering efficiency is quite independent of the gettering layer thickness; in the steady-state results, obtained for very long gettering times, the ultimate gettering efficiency is in proportion to the gettering layer thickness. Furthermore, the results are quite independent of the substrate resistivity for most practical resistivities. However, gettering will somewhat slow down for $\mathrm{p}^{+}$ materials because Fe has two deep donor levels; Fe-B pair formation is expected in p- type Si.

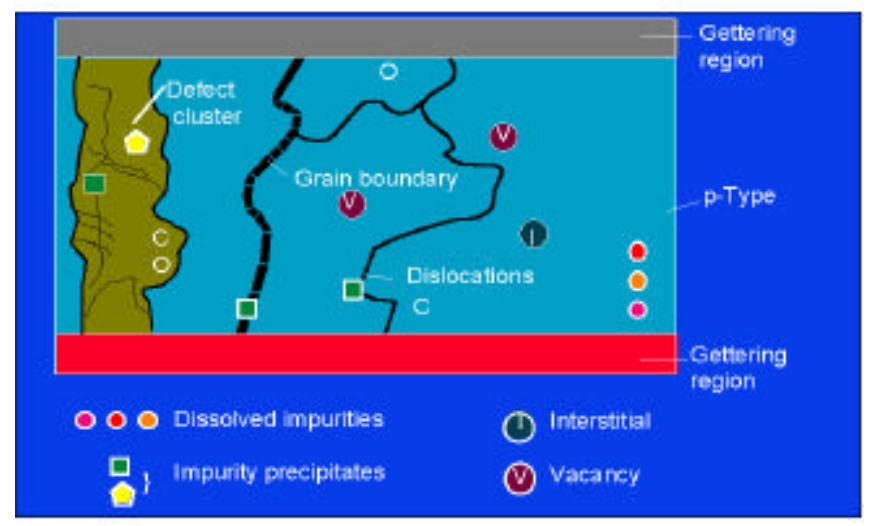

FIGURE 3. A schematic showing different gettering mechanisms inside a lowquality $\mathrm{Si}$ wafers 


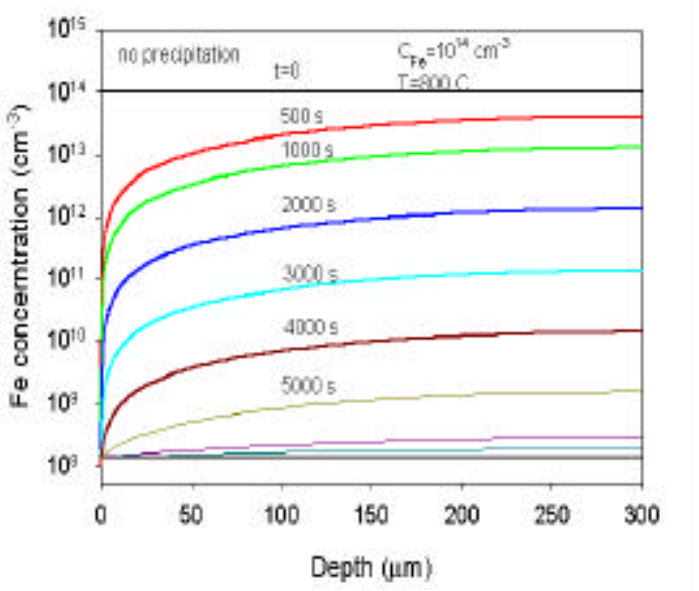

FIGURE 4. Al-gettering simulation at $800^{\circ} \mathrm{C}: 1 \mu \mathrm{m}$ thick $\mathrm{Al}$ layer is placed on the left-hand side of a $300 \mu \mathrm{m}$ thick $\mathrm{Si}$ wafer. The initial dissolved $\mathrm{Fe}$ concentration is $10^{14} \mathrm{~cm}^{-3}$

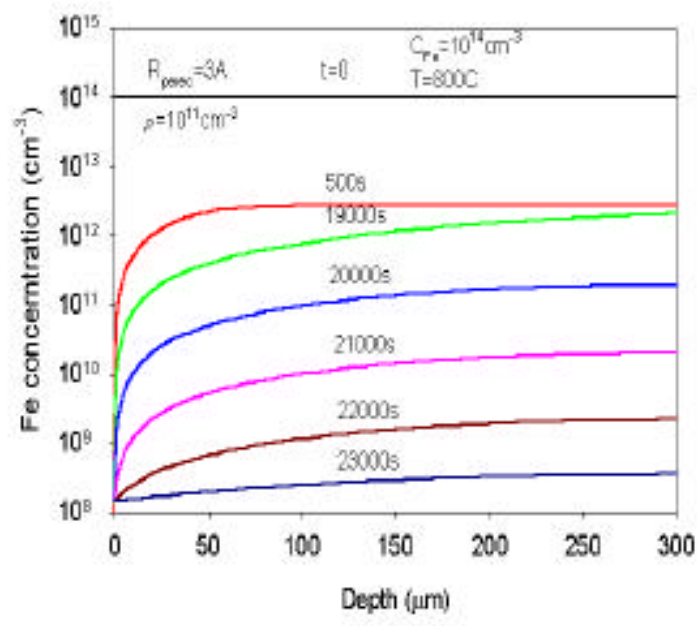

FIGURE 5. Al-gettering simulation at $800^{\circ} \mathrm{C}$ : $1 \mu \mathrm{m}$ thick Al layer is placed on the left-hand side of a $300 \mu \mathrm{m}$ thick Si wafer. The initial dissolved Fe concentration is $10^{14} \mathrm{~cm}^{-3}$, and in addition there is $10^{11} \mathrm{~cm}^{-3}$ silicide precipitates of a radius of $3 \AA$.

Now let us include precipitated $\mathrm{Fe}$ as a silicide in addition to the dissolved $\mathrm{Fe}$ concentration of $10^{14} \mathrm{~cm}^{-3}$. We assume precipitates of $6 \mathrm{~nm}$ in diameter with a concentration of $10^{11} \mathrm{~cm}^{-3}$. The calculated results are shown in Figure 5. An interesting feature is that initially there is a faster decrease in the Fe concentration (compared to the case of Figure 4). This occurs because the precipitates become nuclei where the dissolved $\mathrm{Fe}$, supersaturated at $800^{\circ} \mathrm{C}$, segregates leading to their rapid growth. Although this phenomenon causes an initial improvement of the minority-carrier lifetime, the gettering of Fe atoms to the gettering layer becomes very ineffective. The gettering to the gettering layer starts only after a substantial amount of time after the precipitate dissolution begins. In this case, it will take more than $7 \mathrm{hr}$ to reduce the total Fe concentration to $10^{11} \mathrm{~cm}^{-3}$.

Figure 6 shows the results of the above calculations in a different perspective. It shows total Fe, integrated within the thickness of the wafer, as a function of gettering time (on a normalized scale). In addition, we have included a third case in which the precipitate size is increased to $50 \mathrm{~nm}$. Several features can be observed from this figure: (i) the total concentration of $\mathrm{Fe}$ decreases very rapidly when $\mathrm{Fe}$ is present only in the dissolved state. (ii) When $3 \AA$ precipitates are included, there is a rapid decrease in the soluble Fe followed by a slower decrease that corresponds to the precipitate dissolution, and a rapid decrease beyond this stage. (iii) With larger precipitate size, there is again a rapid initial decrease in the dissolved $\mathrm{Fe}$ concentration, followed by a substantially reduced rate caused by a prolonged dissolution process. It will take many days at $800^{\circ} \mathrm{C}$ to notice any gettering effect.

Some other conclusions form the calculations are: (a) If the precipitates are of the chemically more stable form of Fe oxides or Fe carbides, then gettering times longer than those for the Fe silicide precipitates are needed, because the corresponding Fe solubility will also be lower. (b) We expect that a similar situation holds also for $\mathrm{Cr}$, but only more difficult, because of its lower diffusivity value. At $800^{\circ} \mathrm{C}$, the $\mathrm{Fe}$ 


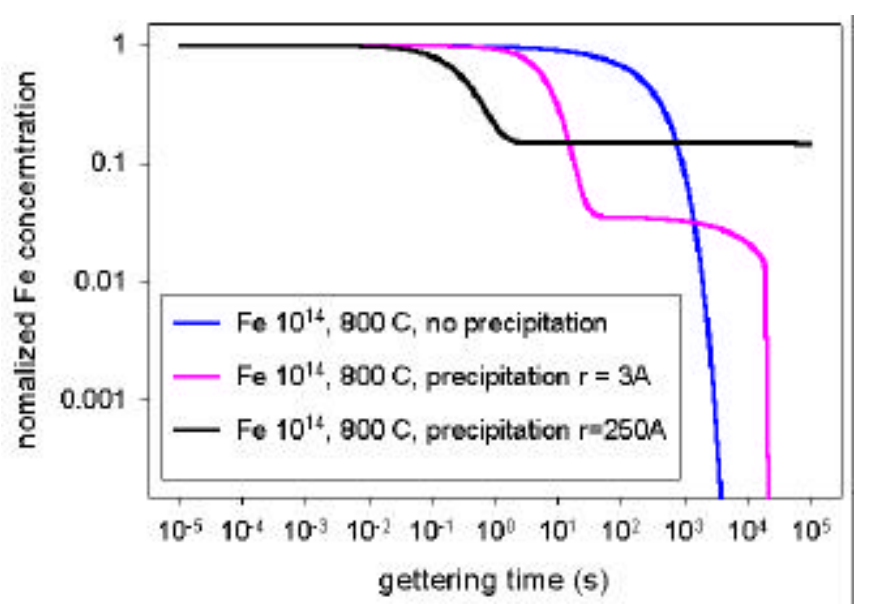

Figure 6. Normalized, total Fe concentration in a 300 $\mu \mathrm{m}$ thick Si wafer (as a function of gettering time) for various conditions of dissolved and precipitated Fe. Precipitated Fe is assumed to be as Fe silicide.

diffusivity is $\sim 10^{-6} \mathrm{~cm}^{2} \mathrm{~s}^{-1}$, while that of $\mathrm{Cr}$ is one order of magnitude lower. (c) Gettering at a temperature much higher than $800^{\circ} \mathrm{C}$ will provide faster precipitate dissolution rate, but this will first result in a decrease of the Si lifetime for a period of time before it can be improved. Also, the final reachable lifetime improvement is decreased. (d) A variable temperature gettering scheme, involving initial gettering at a higher temperature and later on at a lower temperature, either through ramping or through the use of a series of temperature steps, is expected to yield the best result.

The above results clearly explain previous observations that gettering does not occur in the defect cluster regions (5). We have also shown, using an inhomogeneous cell model, that such regions result in local shunts that degrade the cell efficiency by primarily lowering the FF and $V_{o c}(3)$. It is also shown that such regions dissipate power internally within the device. To overcome these effects, the cell uniformity needs to be improved. This can occur only if the defect clusters are either avoided or gettered. Several approaches can be used to lower the effectiveness of defect clusters. One that is being studied within the NREL Si program is the use of RTP. Another approach suggested by the gettering model is to perform gettering where it starts at a high temperature and the temperature is slowly ramped. The third approach is to inject suitable point defects to dissociate precipitates at considerably higher speed. It is important to know that if the impurity concentrations are high, a given process may not be adequate to getter sufficient impurities because of the saturation of the gettering region. It is clear that a material that has high concentrations of impurities and defects will not be fully depleted of the impurities by low-cost processing. In such a case, passivation can play an important role. Some of the recent results of hydrogen passivation are summarized in a recent paper (6).

\section{CELL DESIGN AND PROCESSING}

Substrates with high-impurity and defect concentrations can pose problems that do not occur in a high-quality material. These include high recombination in the bulk, junction shunting, interaction of defects with the metal, high surface recombination in the regions where defects emerge at the surfaces, and propensity 
for defects to interact with impurities during cell processing. These phenomena require additional considerations in cell design and processing to optimize the cell performance. Here we make a brief mention of how these effects can be mitigated.

Thin cells: PV industry uses wafers typically $300-400 \mu \mathrm{m}$ thick, set by sawing and handling abilities. Reducing the wafer thickness is, in general, desirable and particularly important for low-quality wafers to lower the bulk recombination. With the wire sawing technology wafer thickness less than $200 \mu \mathrm{m}$ is feasible.

BSF and surface passivation: It is known that the defects emerging at the surface of a wafer produce higher surface recombination. Likewise, precipitated impurities at the surface can enhance shunting effects. Use of BSF and interface passivation become essential for lower quality substrates. Boron-BSF is preferred over Al-BSF; the latter causes "pitting" and "spiking" that can diminish the effectiveness of BSF.

Metal coverage: Because metals interact heavily at the defect sites, sintering and alloying metal contacts on a defected cell increase the recombination associated with a metal-semiconductor contact. Typical commercial cells can have metal coverage of $7 \%-10 \%$. A lower metal contact area is desired for a lower-quality substrate. Technologies such as buried contact, improved screen printing, direct "writing," and wraparound/wrap-through contacts can help reduce metal coverage. Dopant diffusion under metal fingers can further reduce the metal-related effects.

Cleaner cell processing: In the past, the process cleanliness typically prevalent in the PV industry did not pose a big threat to the cell performance, because the substrate contained higher impurity levels than the furnace. During cell processing, some of the impurities from the substrate out-diffuse or volatilize and contaminate the furnace and other processing equipment, setting up background contamination levels. However, as the substrate quality improves, it is necessary to improve the process cleanliness. Furthermore, indiffusion of impurities can enhance nonuniformities in the cell response, resulting in the lower efficiency.

\section{CONCLUSION}

We have presented a brief review of performance-limiting factors in current commercial Si solar cells. These factors may be viewed in regard to (i) impurities and defects, and (ii) cell and process design. The major issue related to impurities and defects is inefficient gettering in the regions of defect clusters caused by presence of precipitates of metallic impurities. Some approaches to overcome this limitation are addressed. Perhaps use of higher quality feedstock can alleviate this problem. Cell can process designs can be improved to minimize the effects of impurities and defects. Such improvements include thinner cells, reduced interface recombination, reduced metal-Si contact fraction, and improved cleanliness of the process equipment. Overcoming these limitations are expected to raise the cell efficiencies to $18-20 \%$ range.

\section{ACKNOWLEDGEMENT}

This work was supported by the US Department of Energy, under Contract No. DE-AC36-83CH10093. 


\section{REFERENCES}

1. These processes are discussed in several papers in the Procd. of the $8^{\text {th }}$ Workshop on Crystalline Silicon Solar Cell Materials and Processes, Copper Mountain, Colorado, Aug. 1998.

2. B. L. Sopori, "Defect Engineering in Si Solar Cell Processing: A Review," to be published.

3. B. L. Sopori, W. Chen, K. Nemire and J. Gee, "Influence of defect clusters on the performance of silicon solar cells", in Defect and Impurity Engineered Semiconductor II, MRS symposium procd. vol. 510, pp. 505-510, (1998).

4. P. S. Plekhanov, U. M. Goesele and T. Y. Tan, "Improvement of carrier lifetime in silicon by gettering of precipitated impurities," in the Procd of Eighth Workshop on Crystalline Silicon Solar Cell Materials and Processes, 1998, pp. 211.

5. B. L. Sopori, L. Jastrzebski and T. Tan, "A comparison of gettering in single- and multicrystalline silicon for solar cells", in the Procd.. of $25^{\text {th }}$ IEEE photovoltaic Specialist Conference, 1996, pp.625-628.

6. B. L. Sopori et.al., "Hydrogen in silicon: A discussion of diffusion and passivation mechanisms," Solar Energy Materials and solar Cells, 41/42, 1996, p.159-169. 